\title{
A importância da abordagem contextual no ensino de biossegurança
}

\author{
The importance of the contextual approach \\ in the teaching of biosafety
}

\author{
M aria Eveline de Castro Pereira ${ }^{1}$ \\ Pedro César Teixeira Silva ${ }^{2}$ \\ $M$ arco Antonio Ferreira da Costa ${ }^{3}$ \\ ClaudiaJurberg ${ }^{4}$ \\ Cintia de M oraes Borba ${ }^{5}$
}

${ }^{1}$ Comissão Interna de Biossegurança, Instituto Oswaldo Cruz. Av. Brasil 4365 Pavilhão Gomes de Farias Sala 210, M anguinhos. 21045-900 Rio de Janeiro RJ. maria@ioc.fiocruz.br

2 Escola Nacional de Saúde

Pública Sério Arouca,

Fundação Oswaldo Cruz.

${ }^{3}$ Escola Politécnica de

SaúdeJ oaquim Venâncio,

Fundação O swaldo Cruz.

${ }^{4} \mathrm{Núcleo} \mathrm{de} \mathrm{Divulgação} \mathrm{do}$

Programa de Oncobiologia,

Universidade Federal do

Rio de Janeiro.

${ }^{5}$ Laboratório de Taxonomia,

Bioquímica eBioprospecção

deFungos, Instituto

Oswaldo Cruz.
Abstract Biosafety is a field of knowledge that raises questions geared to genetically modified organisms that are linked to social and job-related employee protection. The educational process involves seeking to create a participative and transforming agent and must therefore transcend the simple concept of teaching. Thus, it is important to contextualize biosafety within a constructive teaching strategy by identification of its core concepts - risk, hazard and accident - which allows each individual to understand how risk is perceived within society and dealt with in academia in order to add multiple skills to tackle the situation. Understanding how the relationship between work and health and its consequences and effects are constructed over the course of time, makes it possible to train more critical and well prepared citizens to participate in decisions of a political and social nature that can influence their future. Key words Teaching biosafety, Historical context, Structural concepts
Resumo A biossegurança é um campo do conhe cimento que insere questões voltadas para organismos geneticamente modi ficados e relacionadas à proteção social e ocupacional do trabalhador. 0 seu processo educativo visa à formação deum agente participativo-transformador e, portanto, deve ultrapassar a simplesideia da normalização. Dessa forma, é importante contextualizar a biossegurança dentro de uma estratégia de ensino construtivista com a identificação dos seus conceitos estruturantes - risco, perigo eacidente- que permitam ao indivíduo compreender como o risco é percebido na sociedade e enfocado na academia para, em seguida, agregar múltiplas competências e enfrentá-lo. Conhecer como as relações de trabalhosaúde, suasimplicações eimpactos vem sen do construídas ao longo do tempo, pode formar um cidadão mais crítico e preparado para participar das decisões de ordem político-social que podem influenciar o seu futuro.

Palavras-chave Ensino de biossegurança, Contexto histórico, Conceitos estruturantes 
Introdução

No Brasil, a biossegurança deve ser entendida como um campo do conhecimento que se modela dia-a-dia e transita por dois caminhos distintos que se entremeiam: o primeiro se insere nas questões voltadas aos organismos geneticamente modificados (OGM) e seus derivados; eo segundo nos ambientes onde não estão presentes as atividades inerentes à biotecnologia ${ }^{1}$, mas sim, relacionadas à proteção social e ocupacional dos trabalhadores ${ }^{2}$, podendo, desta forma, ser entendida como biossegurança legal ebiossegurança praticada, respectivamente ${ }^{3}$.

O caráter multidisciplinar da biossegurança, com limites amplos e em constante construçãa ${ }^{4}$, deveser entendido, segundo Carvalho ${ }^{1}$, como um campo de estudos que vai além do ambiente de trabal ho, interagindo de forma dinâmica com as Ciências da $N$ atureza, na qual se encontra fortemente inserida. $O$ autor acredita que a sua inserção no ensino permitiria relacionar temáticas oriundas do ambiente escolar a outros assuntos que os estudantes vivenciam fora da escola.

Entretanto, énecessário contextualizar a biossegurança, dentro de uma estratégia de ensino construtivista com a identificação de seus conceitos estruturantes, pois segundo Garcia Cruz ${ }^{5}$ esses "é que vão transformar o sistema cognitivo dos alunos, de tal maneira, que permitem, de forma coerente, adquirir novos conhecimentos, por construção de novos significados, ou modificar os anteriores, por reconstrução de significados antigos".

N este ensaio, entendemos contextualização como uma estratégia de ensino que incorpora os principais conceitos do campo deestudo, no caso a biossegurança, as práticas cotidianas. Pois, como aponta Pereira, apud Lopes, "educar para a vida requer a incorporação do apreendido em nossas vivências".

Portanto, temos como objetivo discutir a contextualização como estratégia para o ensino da biossegurança.

\section{Ensino de Ciências}

A história, a sociologia e a filosofia da ciência potencializam a humanização das ciências, aproximando-as dos interesses pessoais, éticos, culturais e políticos da comunidade 7 . Desta forma, as aulas de ciências tornar-se-iam mais desafiadoras e reflexivas, permitindo o desenvolvimento do pensamento crítico, dando "sentido" ao conteúdo abordado. 0 objetivo seria fornecer aos estudantes instrumentos que lhes permitam compreender como o conhecimento é construído, suas possi bilidades elimitações, suas rel ações com questões colocadas em domínios relacionados da atividade humana, como a produção e o uso da tecnologia8.

A aprendizagem então deveria ser sobrea natureza da ciência?. Não existe uma definição precisa, nem consensual de natureza da ciência ${ }^{9}$, mas não há como negar queé multifacetada, complexa e dinâmica ${ }^{8}$, uma vez que envolve os resultados de pesquisas de diversas áreas, como a história, a filosofia e a sociologia, além das ciências cognitivas, como a psicologia?.

$M$ artins ${ }^{10}$ ressalta 0 caráter prático e aplicado da história e da filosofia da ciência, que pode ser desenvolvido, de forma integrada, com duas abordagens: a primeira como estratégia didática facilitadora na compreensão de conceitos, modelos e teorias; a segunda como conteúdo (em si) das disciplinas científicas. I sso tem si do enfatizado inclusive nas recomendações curriculares de vários países, como por exemplo, na Inglaterra e, mais recentemente, no Brasil, na edição dos Parâmetros Curriculares Nacionais ${ }^{11}$.

Entretanto, El-H ani ${ }^{12}$ afirma quenão há tempo para tudo que é importante. Então, quais seriam os conceitos estruturantes a serem ensinados? Para Gagliardi ${ }^{13}$, são aqueles cuja construção transforma o sistema cognitivo, permitindo adquirir novos conhecimentos, organizar os dados de outra maneira, transformar inclusive conhecimentos anteriores. 0 autor esclarece ainda que os conceitos estruturantes não são "novos temas" de um programa, mas os objetivos gerais que permitem construir novos conhecimentos.

M iller apud $M$ atthews ${ }^{7}$ acredita que a história eafilosofia da ciência contribuem para a compreensão da ciência. Não épossível compreender ciência sem ter conhecimento da sua dimensão cultural ehistórica. Pensar apropriadamente sobre o conhecimento deum determinado conteúdo requer que se vá além do conhecimento de fatos ou conceitos da área. Ou seja, ao ser capaz de definir aquilo que é aceito como verdade, o indivíduo possa também explicar porque uma dada proposição éconsiderada definitiva ecomo esta se relaciona com outras proposições?.

\section{Abordagem contextual da biossegurança}

Em função dos referenciais descritos anteriormente, levantamos o debate sobre os conceitos estruturantes em biossegurança ${ }^{14}$ compreendida em seu strictu sensu, segundo M arein apud 
Zarate et al. ${ }^{15}$ como um conjunto de normas (entendidas como uma doutrina de comportamento que visa atingir atitudes e condutas que diminuam o risco) definidas para a proteção do homem, da comunidade e do ambiente, do contato acidental com agentes potencialmente perigosos.

N esse contexto, 0 al uno ou o trabal hador não pode ser um mero reprodutor, mas sim um agente participativo-transformador no seu ambiente ocupacional, conjugando o saber fazer-ser-aprender ${ }^{16}$. 0 processo educativo envolve uma ação de reflexão, e segundo Pereira et al. ${ }^{14}$, deve ultrapassar a ideia da simples normatização e abranger, inclusive, aspectos relativos à ética, já que esta está implícita em praticamente todas as ações da biossegurança.

Pereira et al. ${ }^{14}$ apontam como estruturante 0 conceito de risco, ou seja, aquele que é capaz de facilitar o processo de ensino-aprendizagem de biossegurança, mudando o sistema de significação do aluno, permitindo incorporar "coisas" que antes não eram relevantes ou Ihes dava significa$\mathrm{do}^{13}$. Ao conceito estruturante de risco, Costa e Costa ${ }^{17}$ acrescentam dois outros: perigo (causa) e acidente (concretização do risco). Para avaliar riscos, segundo eles, énecessário antesidentificar os perigos que são fontes desses riscos, para que a biossegurança possa ser aplicada de forma a minimizar as consequências de um possível acidente.

Assim, éfundamental conhecer como o risco é percebido na sociedade e enfocado na academia ${ }^{18}$ para, em seguida, agregar múltiplas competências e enfrentá-lo, pois a pessoa ao deparar-se com um determinado perigo, principalmente advindo do processo de trabalho, tende a responder de acordo com suas crenças, experiências, imagens e informações construídas ao longo de sua trajetória de vida ${ }^{19}$.

Beck e Giddens apud Guivant ${ }^{20}$ consideram os riscos, em especial os ambientais e tecnológicos, como chave para entender as características, os limites e as transformações do projeto histórico da modernidade. Essa abordagem permite refletir questões como conflitos sociais, relações entre leigos e peritos, o papel da ciência e formas de fazer edefinir política ${ }^{20}$. O liveira ${ }^{21}$, ao debater sobre a estrutura normativa de segurança e saúde do trabal hador, ressalta queésurpreendenteconstatar que o Direito do Trabalho, a sua marcha evolutiva empenhou-se mais em regulamentar a monetização do risco do que o ambiente de trabalho saudável, assim a proteção à vida e à saúde do trabalhador ficaram em posição secundária.

0 trabalho pioneiro de Bernadino Ramazzini, De morbis artificum diatriba, apesar dos for- matos classificatórios rudimentares em virtude da época em que foram escrito, influenciou as relações sociais de produção, ou seja, a identificação de riscos e carga à saúde no contexto do trabalho ${ }^{22}$. Ramazzini observa o modo de adoecimento das pessoas em mais de 60 ofícios diferentes, relacionando o exercício das atividades e as doenças correlacionadas, indicando ainda o tratamento recomendável eas medidas preventivas ${ }^{21}$.

Mas foi principalmente, segundo Costa ${ }^{2}$, a partir da Revolução Industrial - quando eram inadequadas as condições ambientais agravadas pela falta de higiene nos processos de trabalho, propiciando doenças infecto-contagiosas, ao mesmo tempo em que a periculosidade das máquinas era responsável por mutilações e mortes $^{23}$ - que estudos mais sistematizados foram realizados.

A criação do primeiro "serviço de medicina do trabalho" ocorreu quando uma fábrica têxtil contratou, em 1830, o médico londrino Robert Becker para atuar na prevenção dos danos à saúde resultantes desses $\operatorname{riscos}^{23}$. M inayo-Gomez e Thedim-Costa ${ }^{24}$ destacam que a presença de um médico no interior das unidades fabris representava, ao mesmo tempo, um esforço em detectar os processos danosos à saúde e uma espécie de braço do empresário para recuperação do trabaIhador e o retorno imediato às suas atividades.

A visão bacteriológica firmou-se como paradigma explicativo da relação saúde-doença ${ }^{25}$. A medicina do trabal ho, centrada na figura do médico, orientava-se pela teoria da unicausalidade - para cada doença um agente etiológico refletindo na propensão a isolar riscos específicos, atuando sobre suas consequências, medicando em função de sintomas ${ }^{23}$. Barata ${ }^{26}$ lembra que os agentes etiológicos, apesar de serem causas necessárias, não são suficientes no sentido de que dependem de outros fatores para produzirem alterações morfológicas funcionais e doença. 0 autor esclarecequeno modelo multicasual, a realidade é fragmentada em um conjunto de fatores; o biológico é apenas um dos "fatores de risco".

As mudanças nos processos produtivos decorrentes das duas grandes guerras mundiais e os esforços de reconstrução pós-guerra deram forma a novos problemas e necessidades de saúde relacionadas ao trabalho, corroborando para que outros profissionais se juntassem à equipe médi$\mathrm{ca}$, enfocando aspectos de higiene, ergonomia e segurança do trabalho, conformando a prática da saúde ocupacional ${ }^{27}$. A racionalidade "científica" da atuação multiprofissional e a estratégia de 
intervir nos locais de trabalho, com a finalidade de controlar riscos ambientais, refletem a influência das escolas de saúde pública americanas ${ }^{24}$.

A epidemiologia social vem substituir o conceito decausalidade pelo conceito de determinação social, buscando compreender a relação dialética entre determinantes que atuam no plano geral da constituição da sociedade. A produção social da saúdee doença supera a concepção biologicista linear desimples causa- efeito, eestá vinculada à compreensão dos "modos e estilos de vida" ${ }^{28}$, que pode ser definido como um conjunto relativamente integrado de práticas individuais voltadas para necessidades utilitárias e que representam vestígios da identidade de cada ser, pois, além do "como agir", refere-se a "quem ser". Somando à personalidade individual os valores sociais, bem como as características econômicas e institucionais próprias às ditas democracias ocidentais no que se refere à relação com emprego, o lazer e a vida familiar ${ }^{29}$.

Assim, o trabalho, entendido como uma atividade humana, tem implicação direta sobre 0 processo saúde-trabalho ${ }^{30}$. Marx apud Lima e Samohyl ${ }^{31}$ salienta que o trabalhador passa a maior parte de sua vida no processo de produção. Então, essas condições do processo de produção são, em grande parte, o processo ativo de sua própria vida. Caso as consequências do trabalho sejam nefastas à saúde do trabal hador, dirse-á que é patogênico ${ }^{32}$. Dessa forma, o debate em torno dos riscos éum importante instrumento de democratização nos locais do trabal ho eda própria sociedade, pois coloca em discussão quem, como e com que critérios são definidos riscos para a vida do trabalhador, das pessoas em geral e do ambiente ${ }^{33}$.

\section{Ensino de biossegurança contextualizado}

0 cidadão tem direito de aprender muito mais do que conceitos estanques. 0 contexto histórico deve ser analisado e considerado como uma realidade cultural que contribui de forma decisiva para mudanças sociais ${ }^{34}$. Encarar a ciência como um produto acabado, confere ao conhecimento científico uma falsa simplicidade, além de contribuir para a formação de atitude ingênua frente à ciência ${ }^{35}$. Esta não assume um caráter linear, evolutivo ou cumulativo, mas apresenta múltiplas ramificações, debates, confluências e simultaneidade deargumentos ${ }^{20}$, não sendo, portanto, decorrente de um somatório de experiências positivas ou fruto do trabalho de um único indivíduo ${ }^{36}$.

A ausência do contexto histórico mais amplo transmitea ideia dequea ciência éhermética, que os cientistas não sofriam influências dos aspectos socioculturais em que trabal havam ou mesmo dos conceitos vigentes à época em outros campos do conhecimento ou, ainda, das implicações políticas das opiniões que estavam sendo geradas pela ciência ${ }^{37}$.

A formalização de um saber é um processo histórico e sociopolítico de "depuração" de um discurso com pretensões de verdade, no sentido do estabelecimento e da legitimação de pressupostos e procedimentos conceituais ${ }^{38}$. Dessa forma, é importante que, o ensino da biossegurança aborde todas as possíveis conexões dos seus conteúdos, isto é, passe pelas imbricações históricas, humanas, sociais, éticas, econômicas, políticas, ambientais etécnicas, tendo como pano de fundo, exatamente suas ideias centrais, ou seja, seus conceitos estruturantes ${ }^{14}$.

\section{Considerações Finais}

O ensino contextualizado da biossegurança, relacionado aos saberes prévios dos alunos e aos cotidianos, pode ser uma estratégia eficaz para 0 desenvolvimento de competências nesse campo, queécada vez mais exigido no mundo globalizado atual, principalmente, nas relações trabal hosaúde. E através do ensino debiossegurança contextualizado, pode ser possível conhecer as etapas evolutivas dessas relações e as medidas preventivas elaboradas ao longo do tempo.

0 cidadão crítico poderá debater a partir dos pressupostos teóricos que fundamentam essas construções - suas implicações e consequências - e participar das decisões de ordem políticasocial que podem influenciar seu futuro. 


\section{Colaboradores}

M EC Pereira, PCT Silva, M AF Costa, C Jurberge CM Borba participaram igualmente de todas as etapas de elaboração do artigo.

\section{Referências}

1. Carvalho PR. 0 olhar docente sobre a biossegurança no ensino de ciências: um estudo em escolas da rede pública do Rio de Janeiro. [dissertação]. Rio de Janeiro: Instituto Oswaldo Cruz; 2008.

2. Costa MAF. Construção do conhecimento em saúde: o ensino de biossegurança em cursos de nível médio na Fundação Oswaldo Cruz. [tese]. Rio de Janeiro: Instituto Oswaldo Cruz: 2005.

3. Costa MAF. Qualidade em biossegurança. Rio de Janeiro: Qualitymark; 2000.

4. Borba CM, Armôa GRG. Biossegurança em laboratórios de microbiologia. M icrobiologia in Foco 2007; 2:13-19.

5. García Cruz CM. De los obstáculos epistemológicos a los conceptos estructurantes: una aproximación a la enseñanza-aprendizaje del a geología. Enseñanza de las Ciencias 1998; 16(2):323-330.

6. Lopes AC. Os Parâmetros Curriculares Nacionais para o ensino médio e a submissão ao mundo produtivo: o caso do conceito de contextualização. Educação \& Sociedade 2002; 23(80):386-400.

7. Matthews MR. História, Filosofia e ensino de ciências: a tendência atual de aproximação. Caderno Catarinense de Ensino de Física 1995; 12(3):164-164.

8. Teixeira ES, Freire Jr O, El-Hani CN. A influência de uma abordagem contextual sobre as concepções acerca da natureza da ciência de estudantes de física. Ciência \& Educação 2009; 15(3):259-556.

9. Alves MTS, Henrique AB. Pensamento epistemológico no ensino de física: uma investigação preliminar no ensino médio. In: XVIII Simpósio Nacional de Ensino de Física; 2009; São Paulo. [acessado 2012 maio 3]. Disponível em: http://www.sbf1.sbfisica. org.br/eventos/snef/xviii/sys/resumos/T0687-1.pdf

10. Martins AF. História e filosofia da ciência no ensino: há muitas pedras nesses caminhos. Caderno Brasileiro Ensino Física 2007; 24(1):112-131.

11. Medeiros A, Bezerra Filho S. A natureza da ciência e a instrumentação para o ensino da física. Ciência \& Cognição 2000; 6(2):107-117.

12. El-Hani CN. U ma das coisas boas de estar no tempo é poder olhar para trás. In: Borges RR, organizador. Filosofia e história da ciência no contexto da educação, vivência e teorias. Porto Alegre: PUC/RS; 2007. p.168-194.

13. Gabliardi R. Los conceptos estruturales en el aprendizaje por investigación. Enseñanza de las Ciencias 1986; 4(1):30-35.

14. Pereira MEC, Costa MAF, Costa M FB, Jurberg C. Reflexões sobre conceitos estruturantes em biossegurança: contribuições para o ensino de ciências. Ciência \& Cognição 2009; 14(1):296-303.

15. Zarate de Gelfo AM, Silvina Rezzonico M, Castillo $M C$, Castillho $B$, Bregains L, I razusta $M L$, Priotto E. Bioseguridad e higiene en la formación del odontólogo. Acta Odontológica Venezolana 2009; 47(1):102-109.

16. Costa MAF, Costa M FB. A biossegurança na formação profissional em saúde: ampliando o debate. In: Pereira JB, Ribeiro CG, organizadores. Estudo de Politécnica e Saúde. V. 2. Rio de Janeiro: EPSJV, Fiocruz; 2007. p. 253-272. 
17. Costa MAF, Costa MFB. Educação em biossegurança: contribuições pedagógicas para a formação profissional em saúde. Cien Saude Colet 2010; 15 (Supl.1):1741-1750.

18. Rangel-S ML. Comunicação no controle de risco à saúde e segurança BA sociedade contemporânea: uma abordagem interdisciplinar. Cien Saude Colet 2007; 12(5):1375-1385.

19. Peres F, Rozemberg B, Lucca SR. Percepção de ris$\cos$ no trabalho rural em uma região agrícola do Estado do Rio de Janeiro, Brasil: agrotóxicos, saúde e ambiente. Cad Saude Publica 2005; 21(6):1836-1844.

20. Guivant J. A trajetória das análises de risco: da periferia ao centro da teoria social. Revista Brasileira de Informações Bibliográficas 1998; 46:3-38.

21. Oliveira SG. Estrutura normativa da segurança e saúde do trabalhador no Brasil. Revista do Tribunal Regional do Trabalho 3a. Reg. 2007; 45(75):107-130.

22. Vaconcelos LCF, Gaze R. A integralidade e doenças dos trabalhadores. 0 método de Bernadino Ramazzini. In. O ficina de artigos da pós-graduação em Saúde Pública; 2005; Rio de Janeiro. [acessado 2012 maio 3]. Disponível em: http://www.segurancaetrabalho. com.br/download/integral-fadel.pdf

23. M endes $R$, Dias EC. Da medicina do trabalho à saúde do trabalho. Rev Saude Publica 1991; 25(5):341349.

24. M inayo-Gomez C; Thedim-Costa SM F. A construção do campo da saúde do trabalhador: percurso e dilemas. Cad Saude Publica 1997; 13(Supl. 2):21-32.

25. Penteado EVBF. Tuberculose no ambiente hospitalar: uma questão da saúde do trabalhador [dissertação] Rio de Janeiro: Escola Nacional de Saúde Pública, Fiocruz; 1999.

26. Barata RB. Causalidade e epidemiologia. História, ciência, saúde 1997; 4(1):31-49.

27. Dias EC, Hoefel MG. O desafio de implementar as ações de saúde do trabalhador no SUS: a estratégia do RENAST. Cien Saude Colet 2005; 10(4):817-828.

28. Bastistella C. Saúde, Doença e Cuidado: complexidade teórica e necessidade histórica. In. Fonseca $A F$, Corbo AMD, organizadores. 0 território e 0 processo saúde-doença. Rio de Janeiro: EPSJV/Fiocruz; 2007. p. 25-49.
29. Castiel LD, Guilam MCR, Ferreira MS. Correndo o risco: uma introdução aos riscos em saúde. Rio de Janeiro: Editora Fiocruz; 2010.

30. Madeira LM, Alevs M. Processo saúde-doença e trabalho. Semina: Ciências Biológicas e da Saúde 1996; 7(2):164-169.

31. Lima FPA, Samohyl RW. Determinantes da insegurança no trabalho. Ensaios FEE 1986; 7(1):179-196.

32. Dejours CA. A loucura do trabalho: estudo da psicologia do trabalho. São Paulo: Oboré; 1998.

33. Porto MFS. Análise de riscos nos locais de trabaIho: conhecer para transformar. Caderno de Saúde do Trabalhador. São Paulo: Instituto Nacional de Saúde do Trabalhador; 2000.

34. Pinheiro NAM, Silveira RM CF, Bazzo WA. Ciência, tecnologia e sociedade: a relevância do enfoque CST para o contexto do ensino médio. Ciência \& Educação 2007; 13(1):71-84.

35. Castro RS, Carvalho AM P. História da ciência: investigando como usá-la num curso de segundo grau. Caderno Catarinense de Ensino de Física 1992; (9) 3:238-244

36. Gabliardi R, Giordan A. La historia de las ciencias: una herramienta para la enseñanza. Enseñanza de las Ciências 1986; 4(3):253-258.

37. Carneiro MHS, Gastal ML. História e Filosofia das Ciências no ensino de Biologia. Revista Ciência e Educação 2005; 11(1):33-39.

38. Ayres JRCM. Epidemiologia, promoção da saúde e o paradoxo do risco. Revista Brasileira de Epidemiologia 2002; 5(Supl.1):28-42.

Artigo apresentado em 18/10/2011

A provado em 23/01/2012

Versão final apresentada em 09/02/2012 